\title{
Usage of Contraceptive and Birth Interval in Ethiopia: Systematic Review and Meta-analysis
}

\author{
Abiyu Ayalew Assefa ${ }^{1}$, Kaleab Tesfaye Tegegne ${ }^{1, ~}$, Eleni Tesfaye Tegegne ${ }^{2}$, Mekibib Kassa Tessema ${ }^{3}$, \\ Andualem Zenebe ${ }^{1}$, Wosenyeleh Semeon Bagajjo ${ }^{4}$ \\ ${ }^{1}$ Department of Public Health, Hawassa College of Health Science, Hawassa, Ethiopia \\ ${ }^{2}$ School of Nursing College of Medicine and Health Science, University of Gondar, Gondar, Ethiopia \\ ${ }^{3}$ Leishmania Research and Treatment Center, University of Gondar, Gondar, Ethiopia \\ ${ }^{4}$ Hawassa College of Health Science, Hawassa, Ethiopia
}

Email address:

Kaleabtesfaye35@gmail.com (K. T. Tegegne)

${ }^{*}$ Corresponding author

\section{To cite this article:}

Abiyu Ayalew Assefa, Kaleab Tesfaye Tegegne, Eleni Tesfaye Tegegne, Mekibib Kassa Tessema, Andualem Zenebe, Wosenyeleh Semeon Bagajjo. Usage of Contraceptive and Birth Interval in Ethiopia: Systematic Review and Meta-analysis. Journal of Family Medicine and Health Care. Vol. 7, No. 1, 2021, pp. 7-13. doi: 10.11648/j.jfmhc.20210701.12

Received: January 18, 2021; Accepted: February 7, 2021; Published: March 4, 2021

\begin{abstract}
Background: Children born soon after previous birth are at high risk for health problems and died at a younger age, especially if the interval between the births is less than two years. The purpose of this review is to summarize the evidence whether contraceptive use is associated with birth interval among women in Ethiopia. Methods: Studies for this meta-analysis were accessed through main databases searches (PUBMED and Advanced Google Scholar) that were published from 2010 onwards. Three blinded reviewers evaluated the abstracts as well as the full texts and performed the data extraction. To assess external and internal validity, a risk-of-bias tool was used. Pooled effect size of birth interval was estimated from the reported proportion of eligible studies using RevMan V. 5.3 software. Results: Thirteen studies were found to be eligible and included in the meta-analysis. A total of 16311 women were involved. Of which, 6112 (37.5\%) women had contraceptive users and 5873 $(36 \%)$ of women had experienced short birth interval. The final pooled effect size after trim and fill analysis in random effect model was found to be $-0.67(95 \% \mathrm{CI}:-0.74,-0.59)$. This indicated that presence of a significant association between contraceptive use and the length of birth interval. Conclusions: This meta-analysis found that, in Ethiopia, promoting contraceptive use was associated with decreasing short birth interval by $33 \%$. Thus, the existing efforts of optimizing birth interval should be enhanced through modern contraceptive use.
\end{abstract}

Keywords: Contraceptive Use, Meta-analysis, Birth Interval, Systematic Reviews

\section{Introduction}

Short birth interval defined as the time interval between two births that causes negative effects on mothers and neonates [1]. World Health Organization (WHO) suggested that the suitable interval from birth to next pregnancy is at least 24 months [2]. Several studies indicated that association exists between short birth interval and high infant mortality $[3,4]$.

Ethiopia has large number of neonatal death associated with short birth interval compared to average rate of neonatal death in Africa [5]. Short birth increase maternal malnutrition
[6].

Promoting the length of birth intervals for two years leads to reduction of infant death by $50 \%$ in Ethiopia [5]. Studies suggest that, there is difference in women's birth spacing practice worldwide. Demographic and socioeconomic characteristics influence women's spacing practices, the health of a child and mother and the major difference in women's in birth spacing, is mainly caused by variation in Bongaarts's proximate determinants of fertility [7, 8].

The main factor associated with short birth interval in developing countries is not usage of contraception after birth. As a result woman become pregnant once fecundity returns 
[9].

The result of this systemic review and meta-analysis would be helpful for policy makers of how contraceptive use and birth interval situation looks like in Ethiopia and to design appropriate intervention for promoting utilization of contraceptive so as to decrease child birth and maternal mortality.

Furthermore, the findings of this review will be used as a base line data for health care planners and researchers.

\section{Methods}

Data sources and search strategy

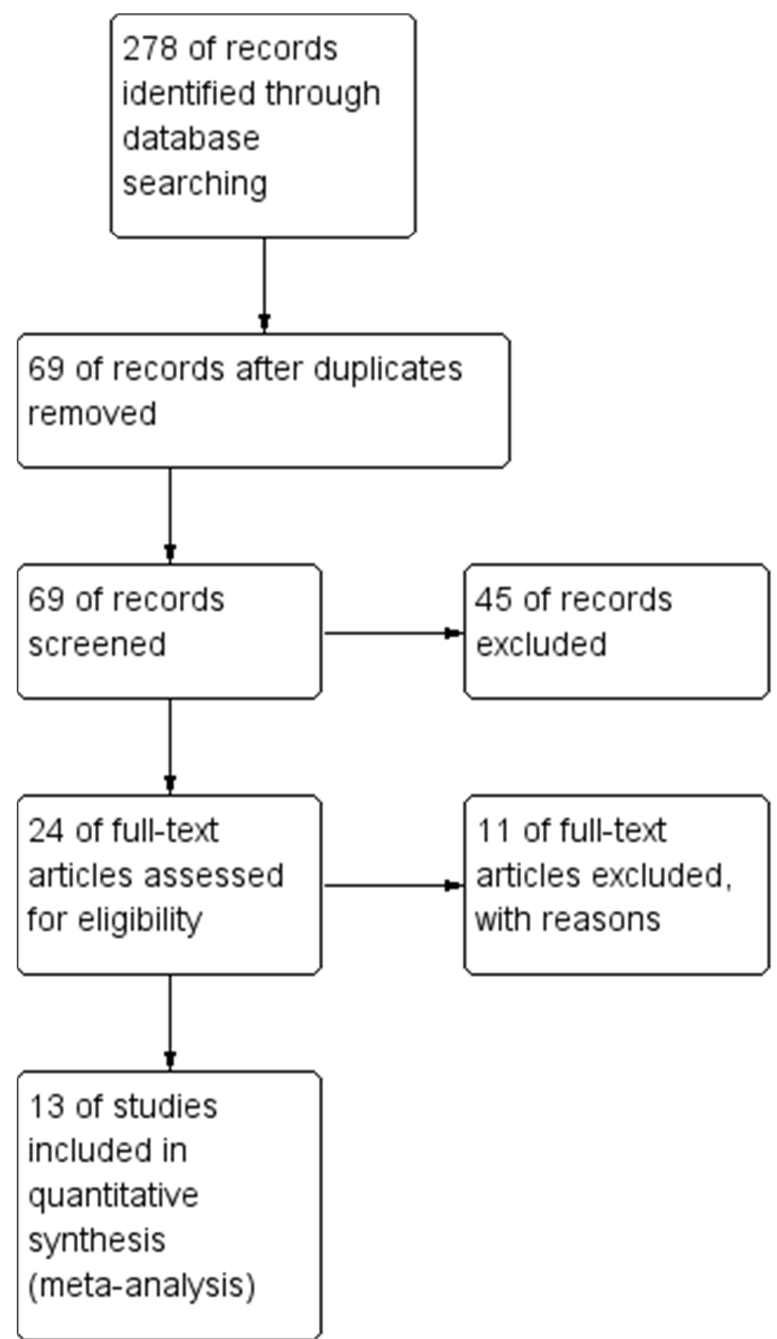

Figure 1. Study flow diagram showing the procedure of selecting studies for meta-analysis, 2020, Ethiopia.

Studies for this meta-analysis were retrieved through different data bases. The researchers were used the following terms: determinant, risk factor, cause, birth interval, contraceptive, contraceptive use, Ethiopia and combination of those words using the Boolean operator.

The databases searched were PUBMED, MEDLINE, WEB OF SCIENCE and Google Scholar. After selecting articles, their references were used to identify similar articles. This review was conducted from December 1, 2020-December 20, 2020. It was conducted in accordance with the Preferred Reporting Items for Systematic Review and Meta-Analyses PRISMA 2009) statement with a 27- items checklist [10].

\subsection{Inclusion Criteria}

Studies were included in the review if; (1) the study was an observational study (cross-sectional study, case-control study, or cohort study), (2) the outcome of interest was birth interval, (3) the study reported the number of birth interval, according to contraceptive use and (4) reports made from 2010 onwards.

\subsection{Exclusion Criteria}

Articles not assessed the association between contraceptive use and birth interval.

\subsection{Data Extraction}

The articles were appraised by three blinded reviewers. After going through the full manuscript abstracts having methodological problems and rejected by the two independent reviewers.

Quality of the reviewed studies was checked based on their topic, objectives, and methodology. Initial assessment was made and some articles were excluded at the first step based on their topic.

On the second step articles were seen and based on that, the articles were disqualified if, they did not match to the current study objectives. For the rest, the whole content of the articles were accessed and selected based on the independent (contraceptive use) and dependent variables (length of birth interval) under review.

\subsection{Operationalization of Outcome Measures}

The outcome variable was a short birth interval (SBI) which was categorized into "Yes $=1 / \mathrm{No}=0$ ". A birth that occurred at less than 24 months following a previous birth in two successive births was classified as having SBI [11].

\subsection{Risk of Bias and Quality Assessment}

A risk-of-bias tool was used to assess risk of bias. The tool has seven items: 1) random sequence generation (selection bias), 2) allocation concealment (selection bias), 3) blinding of participants (performance bias), 4) blinding of outcome assessment (detection bias), 5) incomplete outcome data (attrition bias), 6) selective reporting (reporting bias) and 7) other bias. All of these items are rated based on the author's subjective judgement given responses to the preceding seven items rated as low, moderate or high risk [12].

Additionally, all potential confounding variables were controlled by multivariable analysis in all included studies.

\subsection{Statistical Analysis}

The data was extracted from each selected study by using a 
format prepared in Microsoft Excel spreadsheet and transferred to Meta-essential and Revman software for further analysis.

Pooled effect size of short birth interval was estimated from the reported proportion of selected studies using RevMan V. 5.3 software. Forest plots were produced by displaying $\mathrm{MH}$ odd ratio with their corresponding 95\% CIs for included study. There is statistical significant heterogeneity among studies $\left(\mathrm{I}^{2}=95 \%, \mathrm{p}<0.05\right)$ and we used Random effects model to estimate the DerSimonian and Laird's pooled effect [13].

\subsection{Assessment of Heterogeneity}

To examine the magnitude of the variation across studies, we will consider the heterogeneity by using the $\mathrm{I}^{2}$ measure and its $p$ value [14]. Meta regression was undertaken by taking the sample size and prevalence of short birth intervals to identify the possible source of heterogeneity.

\subsection{Assessment of Reporting Biases}

Funnel plot and Egger's test was used to check reporting biases [15]. Thus, the results of the test suggested a possible existence of a significant publication bias $(p<0.002)$ in Egger's test), the final effect size was determined by applying Trim and Fill analysis in the Random-effects model.

\section{Result}

\subsection{Studies Identified}

The search resulted in 278 records. 120 articles were found in PUBMED, MEDLINE, WEB OF SCIENCE and Google Scholar. After removing duplicates removed, 69 records screened, of which 45 records excluded during the initial assessment as their titles found to be irrelevant. Twenty four full text articles assessed for eligibility. However, 11 articles excluded because they were not assessed contraceptive use and birth interval. Finally, 13 studies were included in the meta-analysis (Figure 1).

\subsection{Study Characteristics}

Out 13 studies included in the meta-analysis, one study was national based study [16].

Four studies were used unmatched case control study design and the other articles were used crossectional study design (Table 1).

The sample size of included studies was ranged from 7740 for the National Ethiopian Demographic Health Survey in the crossectional study from Ethiopia [16] to 314 Serbo Town [17] (table 1). Out of 13 studies included in the meta-analysis, 16311 women were involved. Of which, 6112 (37\%) women had contraceptive users while the remaining 10199 women were non-user of contraceptive and 5833 (36\%) of women had experienced short birth interval. (Table 1).

Table 1. Characterstics of included studies in Ethiopia, 2020.

\begin{tabular}{llll}
\hline S. $\mathbf{N}$ & Author & Study area & Study design \\
\hline 1 & Regasa. Z [16] & Ethiopia & Crossectional \\
2 & Yohannes. S [18] & Lemo district. & Crossectional \\
3 & Begna. Z [19] & Yaballo Woreda, & Case control \\
4 & Hailu. D [20] & Arba Minch Zuria District, & Case control \\
5 & Muluneh. A [21] & Gedeo Zone & case control \\
6 & Aychiluhm. S [22] & Afar, Somali, Gambella, and Benishangul-Gumuz Regions & Crossectional \\
7 & TSADIK. M [23] & Maichew town, & Crossectional \\
8 & Gebrehiwot. S [24] & Tselemti district & Crossectional \\
9 & Ejigu. A [25] & Debremarkos & Crossectional \\
10 & Ayane. G [17] & Serbo Town & Crossectional \\
11 & Tsegaye. D [26] & Illubabor zone & Crossectional \\
12 & Shallo. S [27] & Dodota Woreda, & Crossectional \\
13 & Hailemeske. H [28] & Dessie city administration & case control \\
\hline
\end{tabular}

Table 1. Continued.

\begin{tabular}{|c|c|c|c|c|}
\hline S. $\mathbf{N}$ & Total sample size & Contraceptive user & Contraceptive non user & Short birth interval (\%) \\
\hline 1 & 7740 & 2113 & 5606 & 25 \\
\hline 2 & 811 & 447 & 364 & 57 \\
\hline 3 & 652 & 298 & 338 & 51 \\
\hline 4 & 636 & 349 & 287 & 47 \\
\hline 5 & 814. & 544 & 270 & 51 \\
\hline 6 & 2683 & 117 & 1992 & 46 \\
\hline 7 & 605 & 270 & 335 & 59 \\
\hline 8 & 806 & 618 & 185 & 25 \\
\hline 9 & 418. & 257 & 100 & 41 \\
\hline 10 & 314 & 197 & 117 & 68 \\
\hline 11 & 826. & 164 & 66 & 51 \\
\hline 12 & 426 & 229 & 394 & 48 \\
\hline 13 & 678 & 509 & 145 & 33 \\
\hline
\end{tabular}


From thirteen studies, Ten of them were showed a statistically significant association between contraceptive use and short of birth interval [17-20, 23-28] while, three studies did not showed a statistically significant association between contraceptive use and short of birth interval [16, 21, 22].

\subsection{Association of Contraceptive Use and Birth Interval}

The pooled effect size of short birth interval among contraceptive user was $0.31(95 \%$ CI: $0.21,0.47)$ as compared contraceptive non-user (Figure 2).

Odds Ratio Odds Ratio

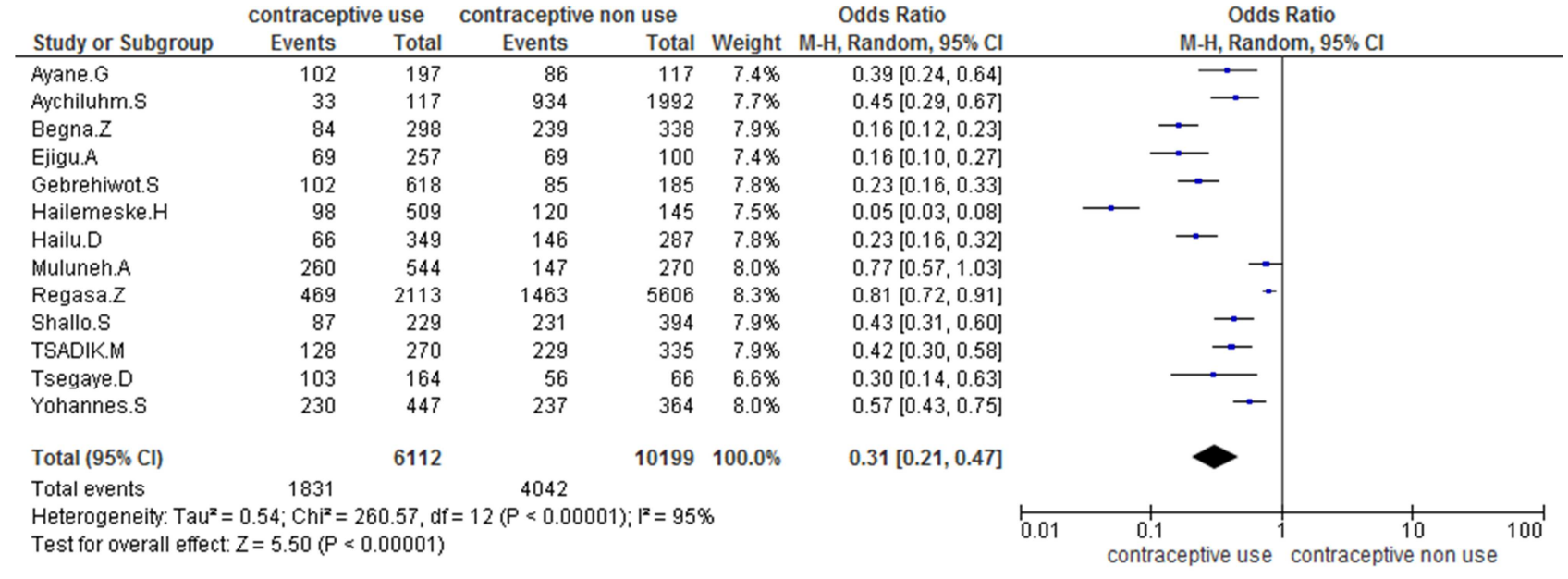

Figure 2. Forest plot that show the association between contraceptive use and short birth interval in Ethiopia, 2020.

\subsection{Source of Heterogeneity}

Meta regression analysis revealed that, sample size and effect size of short birth interval had significant difference, i.e. as sample size increases, effect size also increases $(\mathrm{B}=0.01, \mathrm{P}$-value $<0.001)$ (Figure 3).

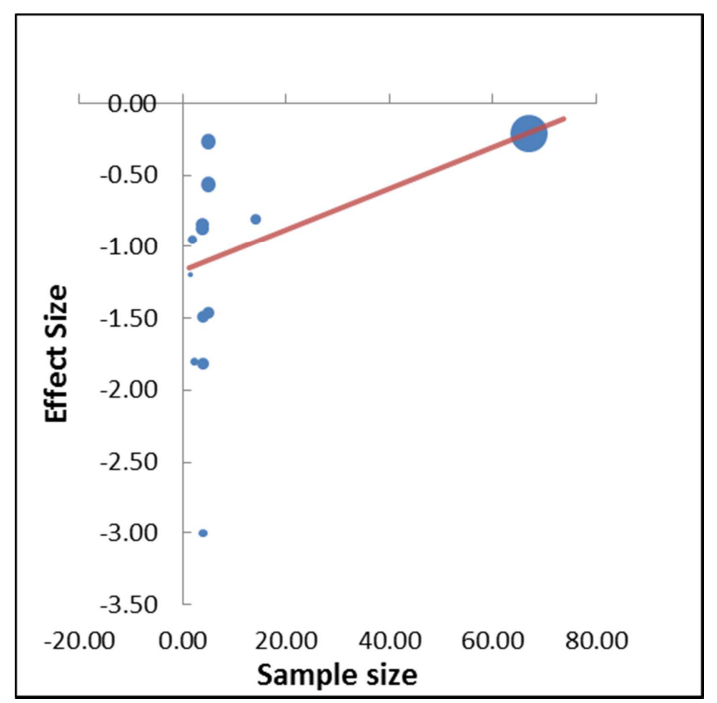

Figure 3. Meta regression analysis of sample size and effect size of short birth interval in Ethiopia, 2020.

\subsection{Moderator Analysis}

We quantitatively explores interactions between the risk of short birth interval in contraceptive user vs contraceptive non user, as expressed with odds ratios and a moderator or covariate of interest is prevalence of shorth birth interval in each study.

Accordingly, the moderator analysis indicated that as prevalence of short birth interval decrease the effect size of of short birth interval increases $(B=-0.02, \mathrm{P}$-value $<0.001)$ (Figure 4).

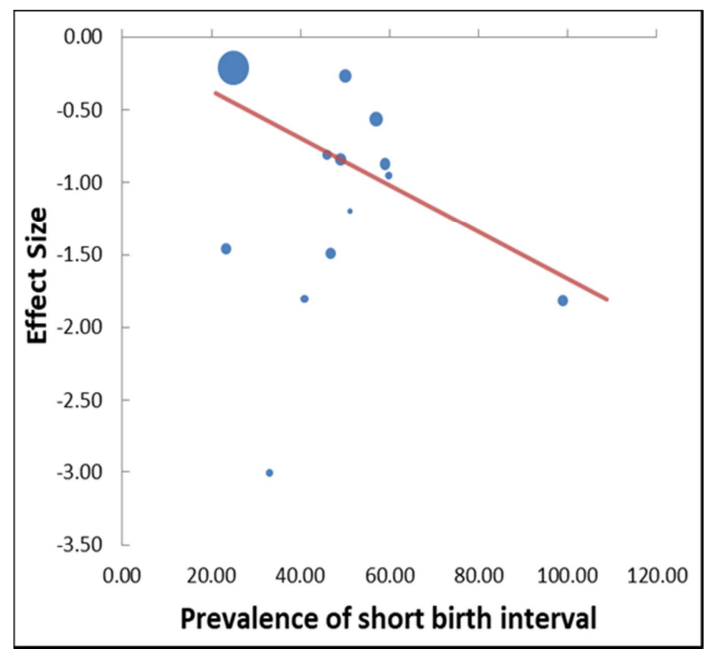

Figure 4. Moderator analysis of prevalence of short birth interval and effect size in Ethiopia, 2020.

\subsection{Assessment of Reporting Bias}

The funnel plot was asymmetric and Egger's test of the intercept (Bo) was found to be -7.19 (95\%CI: $-11.13,-3.24$ $\mathrm{P}=0.002$ ), this indicates the presence of publication bias. Because of this, we have done trim and fill analysis to adjust the final pooled effect size. This method indicated that ten studies are missing on the right side of the mean size based on random effect model. So the final pooled effect size after trim and fill was found to be -0.67 (95\% CI: $-0.74,-0.59$ ). This showed the presence of a significant association 
between contraceptive use and the short birth interval (Figure $5)$.

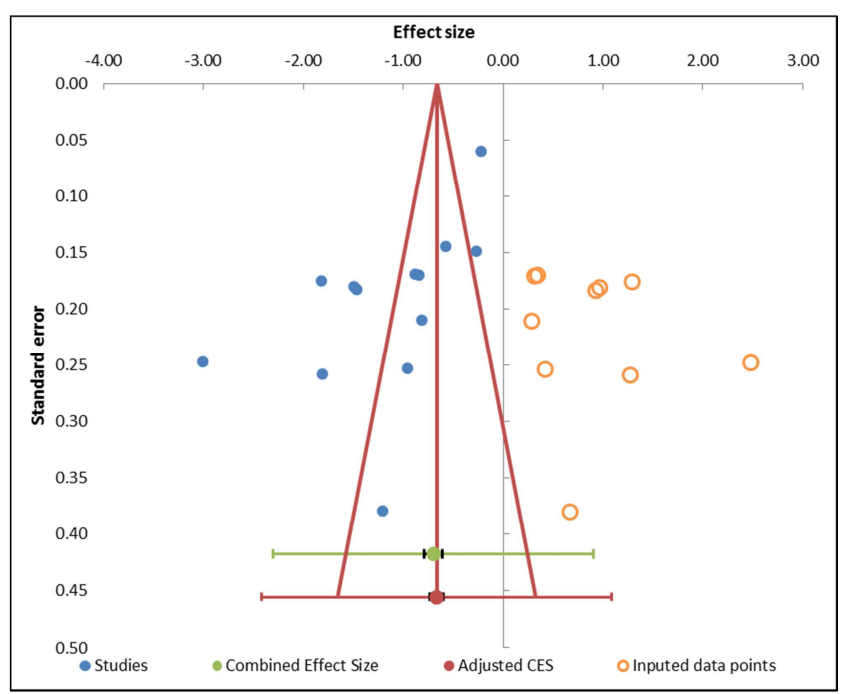

Figure 5. Funnel plot to show the effect of contraceptive use on short birth interval in Ethiopia, 2020

\section{Discussion}

This review will provide pooled estimates of contraceptive use and short birth interval in Ethiopia.

In this study the final pooled effect size after trim and fill analysis in random effect model was found to be -0.67 (95\%CI: $-0.74,-0.59)$ and Moderator analysis indicated that as prevalence of short birth interval decrease the odds of short birth interval increases $(\mathrm{B}=-0.02, \mathrm{P}$-value $<0.001)$ (Figure 4).

Our result is comparable with previous studies done in Ethiopia [17-21, 23, 25, 28 29] and other countries Manipur [30], Jordan [31], Ahvaz (Iran) [32], Egypt [33] and Uganda [34] that stated contraceptive use was associated with decreased short birth interval. This might be due to contraceptive use leads to birth spacing by different mechanisms on normal reproductive process [35]. Additionally, contraceptive utilization can delay the pregnancy [36].

Our finding is not similar with previous studies in Ethiopia $[16,21,22]$ and other countries like sub-Saharan Africa [37], India [38] on which contraceptive use is not significantly associated with birth interval. The reason for this difference might arise because of study population, sample size, methodology, sociodemographic, health service access for family planning, and awareness of women's on contraceptive use.

Finally, the study has some limitations like: use of random effect model and trim and fill analysis might overestimate or underestimate the true magnitude. Furthermore, this study uses small number of studies done in Ethiopia. Therefore, the findings of this review should be interpreted in the context of above limitations and the current analysis.

\section{Conclusion}

This study indicated that, contraceptive use was associated with decreasing short birth interval. Thus, to increase birth an interval, strategies targeting promotion of using family planning for reproductive women is recommended.

\section{Data Availability}

All data are included in the paper.

\section{Authors' Contributions}

AAA, KTT and AZ conceived the idea and had major roles in data review, extraction, and analysis. AZ, WSB, ETT and MKT conducted the initial literature searches. All authors (AAA, KTT, AZ, ETT, WSB and MKT) read and agreed to submit to the current journal.

\section{Competing of Interest}

The authors have declared that there is no competing interest.

\section{Funding}

Not any funding received for this work.

\section{Acknowledgements}

We would like to thank all the primary authors of the included articles.

\section{References}

[1] Onde-Agudelo A, Rosas-Bermudez A, Castano F, Norton MH: Effects of birth spacing on maternal, perinatal, infant, and child health: a systematic review of causal mechanisms. Stud Fam Plann2012, 43: 93-114.

[2] WHO: Report of a WHO Technical Consultation on Birth Spacing. Geneva, Switzerland: WHO; 2007. 9-9-2011.

[3] World Health Organization and Department of Making Pregnancy Safer, Technical Consultation Report on Birth Spac-ing, WHO, Geneva, Switzerland, 2005, http://www.who.int/maternalchildadolescent/documents/births pacing.pdf.

[4] United States Agency for International Development (USAID), Strengthening Family Planning Policies and Programs in Devel-oping Countries, United States Agency for International Devel-opment (USAID), Washington, DC, USA, 2005.

[5] Dadi AF. A systematic review and meta-analysis of the effect of short birth interval on infant mortality in Ethiopia. PloSone 2015, $\quad 10 \quad$ (5): 0126759. https://doi.org/10.1371/journal.pone.0126759PMID:26001079.

[6] King JC. Risk of Maternal Nutritional Depletion a n d Poo r Outcome s Increases in Early or Closely Spaced Pregnancies. The Journal of Nutrition. 2003; 133 (5): 1732S-17 36S. 
[7] Huber U. The Determinants of Birth Intervals: A Qualitative Approach from Punjab, India. International Journal of population Geography, 2002, 8: 277-296.

[8] Hinde A, Baschieri A. The proximate determinants of fertility and birth intervals in Egypt: An application of calendar data. January 2007; 16 (3): 59-96.

[9] Nahla A, Sarah L, Amal Z: Helping Egyptian women achieve optimal birthspacing intervals through fostering linkages between family planningand maternal and child health services. Sep.2008.

[10] Moher D, Liberati A, Altman DG, Tetzlaff J,: The PRISMA Statement for Reporting Systematic Reviews and MetaAnalyses of Studies That Evaluate Health Care Interventions: Explanation and Elaboration. PLoS Med 2009, 6 (7): e1000100 doi: 10.1371/journal.pmed.1000100PMID: 1962107.

[11] WHO. Report of a WHO technical consultation on birth spacing: Geneva, Switzerland 13-15 June 2005.

[12] Review Manager 5 (RevMan 5) [Computer program]. Version 5.3. Copenhagen: Nordic Cochrane Centre, The Cochrane Collaboration, 2014.

[13] Higgins JPT, Deeks JJ, and Altman DG: Measuring inconsistency in meta-analyses. BMJ. 2003; 327: 557-560 PMID: 12958120.

[14] Higgins JP, Thompson SG. Quantifying heterogeneity in a meta-analysis. Stat Med 2002; 21: 1539-58.

[15] Knapp G, Hartung J: Improved tests for a random effects meta-regression with a single covariate. Stat Med 2003; 22: 2693-710 PMID: 12939780.

[16] Regasa Z et al Spatial Distribution And Determinant Factors Of Birth Interval Among Reproductive Age Group Women, Based On Edhs 2016, Ethiopia, 2019. DOI: https://doi.org/10.21203/rs.3.rs-21607/v1.

[17] Ayaneet al. Suboptimal child spacing practice and its associated factors among women of child bearing age in Serbo town, JIMMA zone, Southwest Ethiopia Contraception and Reproductive Medicine (2019) 4: 4 https://doi.org/10.1186/s40834-019-0085-1.

[18] Yohanneset al.: Duration and determinants of birth interval among women of child bearing age in Southern Ethiopia. BMC Pregnancy and Childbirth201111: 38.

[19] Begnaet al.: Determinants of inter birth interval among married women living in rural pastoral communities of southern Ethiopia: a case control study. BMC Pregnancy and Childbirth201313: 116.

[20] Hailu. D. Determinants of Short Inter birth Interval among Reproductive Age Mothers in Arba Minch District, Ethiopia International Journal of Reproductive Medicine Volume 2016, $\begin{array}{llll}\text { Article ID } & 6072437, & 17 & \text { pages }\end{array}$ http://dx.doi.org/10.1155/2016/6072437.

[21] Muluneh A. Determinants of Sub-Optimal Birth Spacing in Gedeo Zone, South Ethiopia: A Case-Control Study International Journal of Women's Health 2020: 12 549-556.

[22] Aychiluhm SB, Tadesse AW, Mare KU, Abdu M, Ketema A (2020) A multilevel analysis of short birth interval and its determinants among reproductive age women in developing regions of Ethiopia. PLoSONE15 (8): e0237602. https://doi.org/10.1371/journal.pone.0237602.

[23] Tsadik M. The pattern and determinants of birth interval among married women of reproductive age group, Maichew town, South Tigray. a thesis submitted to school of graduate studies addis ababa university in partial fulfilment of the requirements for the degree of master of public health, 2010.

[24] Gebrehiwotet al Short birth interval and associated factors among women of child bearing age in northern Ethiopia, 2016 BMC Women's Health (2019) 19: 85 https://doi.org/10.1186/s12905-019-0776-4.

[25] Ejigu et al. The efect of sex of last child on short birth interval practice: the case of northern Ethiopian pregnant women BMC Res Notes (2019) 12: 75 https://doi.org/10.1186/s13104-019-4110-x.

[26] Tsegaye. D Practice of child spacing and its associated factors among women of child bearing age (15 to 49 years) in Illubabor zone, South West Ethiopia International Journal of Nursing and Midwifery Vol. 9 (7), pp. 102-108, July 2017 DOI: $10.5897 /$ IJNM2017.0258.

[27] Shallo SA, Gobena T (2019) Duration of Birth Interval and Associated Factors among Married Women in Dodota Woreda, Arsi Zone, Ethiopia. J Health Educ Res Dev 7: 292. doi: 10.4172/2380-5439.1000292.

[28] Shimels Hailemeskel H, Assebe T, Alemayehu T, Belay DM, Teshome F, Baye A, et al. (2020) Determinants of short birth interval among ever married reproductive age women: A community based unmatched case control study at Dessie city administration, Northern Ethiopia. PLoS ONE15 (12): e0243046. https://doi.org/10.1371/journal.pone.024304.

[29] Ayanaw A: Proximate determinants of birth interval length in Amhara region: the Case of Fagita Lekoma woreda, Awizone, (unpublished). Ethiopia Jun: M. Sc thesis Addis Ababa; 2008 .

[30] S. N. Singh, N. Singh, and R. K. Narendra, "Demographic and socio-economic determinants of birth interval dynamics in manipur: a survival analysis, The Online Journal of Health and Allied Sciences, vol. 9, no. 4, article 3, 2010.

[31] R. Youssef, "Duration and determinants of inter-birth interval: community-based survey of women in southern Jordan," The Eastern Mediterranean Health Journal, vol. 11, no. 4, pp. 559$572,2005$.

[32] R. Abdurrahman and M. Majid, "The determinants of birth interval in Ahvaz-Iran: a graphical chain modeling approach," Journal of Data Science, vol. 5, pp. 555-576, 2007.

[33] A. Baschieri and A. Hinde, "The proximate determinants of fertility and birth intervals in Egypt: an application of calendar data," Demographic Research, vol. 16, article 3, pp. 59-96, 2007.

[34] Aleni M., et al. Birth Intervals and Associated Factors among Women Attending Young Child Clinic in Yumbe Hospital, Uganda International Journal of Reproductive Medicine, Volume: 2020, Article ID 1326596, 11 pages, https://doi.org/10.1155/2020/1326596.

[35] WHO. World Health Organization, Contraception Issuesin Adolescent Health and Development. 2004. 
[36] United States agency for International Development. Strengthening family planning policies and programs in developing countries. USA: USAID; 2005, World Health Organization. Report of a WHO Technical Consultation on Birth Spacing Geneva. Switzerland. 2005; 13-15: 2007.

[37] Ngianga-Bakwin K, Stones RW. Birth intervals and injectable contraception in sub-Saharan Africa. Contraception. 2005; 71: 353-6.
[38] Singh R., et al. Determinants of Birth Intervals in Tamil Nadu in India: Developing Cox Hazard Models with Validations and Predictions. Revista Colombiana de Estadística Número especial en Bioestadística Junio 2012, volumen 35, no. 2, pp. 289 a 307. 